\title{
Una aproximación a la revisión de oficio de los actos administrativos en el Derecho chileno ${ }^{1}$
}

\author{
Álvaro Roberto Delgado Lara (Chile) \\ Universidad Bernardo O'Higgins \\ alvaro.delgado17@gmail.com
}

\section{NOTA BIOGRÁFICA}

Profesor de Derecho Administrativo. Doctorando en Derecho Administrativo en la Universidad de Córdoba. Magister en Derecho LLM, mención Derecho Constitucional, por la Pontificia Universidad Católica de Chile.

\section{RESUMEN}

Este trabajo explora y explica en qué consiste la revisión de oficio de los actos administrativos en el derecho chileno, mediante un examen de las diversas vías y causales para obtener la extinción de los actos administrativos establecidas en la Ley de Bases de los Procedimientos Administrativos. Finalmente, se evidencia que la revisión de oficio en Chile se debe entender como un género del cual se desprenden tres especies (invalidación, revocación y aclaración de puntos oscuros o corrección de erratas).

\section{PALABRAS CLAVE}

Invalidación; Revisión de Oficio; Revocación.

\begin{abstract}
This document explores and explains what is the administrative review of administrative acts in Chilean law, through an examination of the various forms and causes to obtain the extinction of the administrative acts established in the Law of Bases of Administrative Procedure. It concludes with the evidence that the review administrative in Chile is a genre that has three species (invalidation, revocation and clarification of obscure points or correction of errors).
\end{abstract}

\section{KEYWORDS}

Invalidation; Administrative Review; Revocation.

\section{SUMARIO}

I. PLANTEAMIENTO DEL PROBLEMA. II. LAS VÍAS ADMINISTRATIVAS DE REVISIÓN Y LAS CAUSALES DE ELIMINACIÓN DE LOS ACTOS ADMINISTRATIVOS EN LBPA. 1. LA EXTINCIÓN NATURAL DE LOS ACTOS ADMINISTRATIVOS. 2. LA EXTINCIÓN PROVOCADA DE LOS ACTOS ADMINISTRATIVOS. 3. LAS VÍAS DE REVISIÓN REGULADAS EN LA LBPA. a) La invalidación. b) La revocación por motivos de oportunidad. c) Las vías recursivas administrativas. d) La aclaración de puntos oscuros, dudosos y rectificación de meros errores. III. LA REVISIÓN DE OFICIO EN SENTIDO AMPLIO. UNA PROPUESTA DE INTERPRETACIÓN ARMÓNICA PARA EL DERECHO CHILENO. 1. LA INVALIDACIÓN COMO UN SUPUESTO DE REVISIÓN DE OFICIO DE LOS ACTOS ADMINISTRATIVOS. 2. UNA JUSTIFICACIÓN DE POR QUÉ LA LBPA NO CONSIDERÓ A LA INVALIDACIÓN DENTRO DEL CITADO PÁRRAFO $4 .^{\circ}$ DEDICADO A LA REVISIÓN DE OFICIO. IV. CONCLUSIONES. V. REFERENCIAS BIBLIOGRÁFICAS.

\footnotetext{
1 Este trabajo se enmarca dentro de mi tesis doctoral que se encuentra en actual desarrollo.
} 


\section{PLANTEAMIENTO DEL PROBLEMA}

Se afirma que en los derechos comparados con una mejor técnica legislativa, la revisión de oficio se suele emplear exclusivamente para referirse a la eliminación de los actos administrativos por iniciativa propia de la Administración Pública y por estrictas razones de ilegalidad (Bocanegra, 2012: 213 y 215). Así queda, por tanto, reservado el término revocación para referirse solo al retiro de un acto administrativo por motivos de mérito, conveniencia u oportunidad. Por lo mismo, Rebollo y Carbonell (2016: 173) han expresado que en el derecho administrativo español «por revisión de oficio de los actos administrativos hay que entender la reconsideración por iniciativa de la propia Administración de sus actos por considerarlos ilegales desde su origen y con el objeto de declarar por sí misma su invalidez originaria». Esto, aun cuando la Ley española núm. 39/2015 incluya bajo el epígrafe revisión de oficio, de su capítulo I (Arts. 106 a 111), del título V, a otras figuras que no son revisión de oficio propiamente tal, como son la revocación por motivos de oportunidad (Art. 109.1) y la rectificación de erratas (Art. 109.2). El fundamento de tal aseveración radica, como bien lo complementa Esteve (2012: 237), en que de la mencionada ley se desprende que «la revocación de los actos es cuando se produce su desaparición por razones de oportunidad: no se advierte vicio alguno en un acto perfectamente ajustado a la legalidad vigente, pero por razones de reconocida conveniencia, la Administración pretende revocarlo, que desaparezca». En cambio, «la revisión de oficio se plantea por razones de estricta legalidad: se considera que el acto que se pretende revisar incurre en algún tipo de vicio o contravención a la legalidad vigente» (Esteve, 2012: 237).

La doctrina alemana, representada para estos efectos por Maurer (2012: 285), no difiere en lo absoluto de lo expuesto, pues nos explicita que la revisión de oficio (rücknahme) es un término que se ha circunscrito únicamente para identificar el retiro o eliminación en sede administrativa de aquellos actos administrativos que son originalmente antijurídicos $(\S 48)^{2}$. En cambio, la expresión revocación (widerruf) es empleada para referirse al retiro de aquellos actos que originalmente son conforme a derecho, es decir válidos, pero que con el paso del tiempo y por diversas circunstancias se han vuelto inoportunos $(\S 49)^{3}$.

De ese modo, se aprecia que un aspecto más o menos asentado en los citados derechos comparados es que la noción de revisión de oficio está rigurosamente ceñida para referirse a la extinción de los actos administrativos que han sido elaborados en forma irregular. Esto es ilegales o contrarios a derecho ${ }^{4}$. Por tanto, la noción de revisión de oficio está ligada a la de invalidación o anulación de un acto administrativo por iniciativa propia de la Administración. Por lo mismo, la distinción entre revisión de oficio y revocación está centrada en las diversas motivaciones concurrentes para la extinción del acto, vale decir ilegalidad o inoportunidad, según corresponda.

Sin embargo, en el derecho chileno pareciera que la regulación legal de la revisión de oficio va por el lado opuesto. Así se entrevé de una primera lectura de la Ley núm. 19.880/2003 de Bases de los Procedimientos Administrativos (en adelante LBPA), en la que, si bien son tres las instituciones que aparecen en esta Ley (Estas son la invalidación ${ }^{5}$, la revocación por motivos de oportunidad y la aclaración de puntos dudosos u obscuros o rectificación de erratas), se puede observar que curiosamente dicha ley ha dejado a la invalidación fuera del apartado específicamente destinado a la revisión de oficio y, en su lugar, ha situado solo a la revocación y a la aclaración o rectificación de erratas.

En efecto, el capítulo IV de la LBPA, cuya designación es «revisión de los actos administrativos», posee cuatro párrafos. En el primero, denominado como «principios generales», se halla la institución de la invalidación de los actos administrativos (Art. 53). En el segundo y tercer párrafo existen otras figuras distintas, pero con las cuales la invalidación guarda alguna afinidad, como son los recursos administrativos de repo-

2 VwVfG, § 48. «Revisión de un acto administrativo ilegal.

(1) Un acto administrativo ilícito puede, en todo o en parte, incluso después que se haya vuelto inimpugnable ser retirado con efectos para el futuro o para el pasado. (...)». La traducción es nuestra.

3 VwVfG, § 49. «Revocación de un acto administrativo legal.

(1) Un acto administrativo legal no favorable puede, incluso desde que sea inimpugnable, ser revocado en todo o en parte con efectos para el futuro, excepto cuando un acto administrativo con el mismo contenido debiera ser dictado nuevamente o si una revocación es inadmisible por otras razones.

(2) Un acto administrativo legal y favorable puede, incluso después de que se haya vuelto inimpugnable, ser completa o parcialmente revocado con efecto para el futuro (...)». La traducción es nuestra.

4 Téngase en consideración que a lo largo de este trabajo se empleará el término ilegal en su sentido amplio, es decir como sinónimo de cualquier antijuridicidad o contrariedad a derecho.

5 Por ahora, anótese que invalidación es la denominación que el derecho chileno ha otorgado a la anulación de los actos administrativos en sede administrativa. (REYES, 2002: 138). 
sición, jerárquico (Art. 59) y extraordinario de revisión (Art. 60). Finalmente, el párrafo cuarto, titulado como «de la revisión de oficio de la Administración», se dedica a la revocación por motivos de oportunidad (Art. 61) y a la aclaración de puntos oscuros o rectificación de meros errores (Art. 62).

Otro antecedente relevante es que el vocablo revisión no ha sido una expresión habitual en la legislación, jurisprudencia o doctrina administrativa chilena. Menos aún lo ha sido el enunciado revisión de oficio. Más bien ha acontecido que la doctrina nacional ha referido y tratado a la invalidación dentro de la teoría de las causales de extinción de los actos administrativos, pero sin hacer referencia alguna a la noción de revisión de oficio (Cfr. Aróstica, 1984: 433-448; Silva, 1995: 152-153; o Abarca, 2015: 99). De ahí que se puede afirmar que la inserción de este enunciado en el ordenamiento jurídico chileno se debe a una auténtica innovación realizada por la LBPA e importada desde el derecho comparado, pero sin una adecuada correspondencia.

De esta manera, si se pretende comprender el significado o sentido de revisión de oficio en el derecho administrativo chileno, lo anterior se vislumbra como un verdadero problema. Especialmente si se observa que las leyes no ofrecen ninguna definición de revisión de oficio, sino que el único antecedente que se tiene sobre esta expresión es que ha sido utilizada por la LBPA como el epígrafe del párrafo $4 .{ }^{\circ}$ («De la revisión de oficio de la Administración») ${ }^{6}$. Siendo así, nos urge determinar en qué consiste y cómo se estructura la revisión de oficio en la LBPA. Como también determinar si la invalidación, a pesar de no hallarse dentro del citado párrafo $4 .^{\circ}$, igualmente, puede ser considerada como un supuesto de revisión de oficio.

A nuestro entender, la respuesta se encamina, en primer lugar, por sostener que aun cuando la historia legislativa de la LBPA evidencia que el derecho hispano ha sido su principal modelo (Biblioteca del Congreso Nacional, 2003: 69, 99, 129, 135 y 179), de su examen, se observa que la revisión de oficio chilena no se condice exactamente con su homóloga hispana. Esto, porque más bien al parecer el legislador chileno solamente se ha servido de las denominaciones que utiliza el derecho comparado, pero en cuanto a la estructura del régimen de revisión de los actos administrativos lo ha configurado de una manera heterogénea. En ese sentido, se afirma que en el derecho administrativo chileno la revisión de oficio es un género que contiene tres especies menores. Esto es la invalidación, la revocación por motivos de oportunidad y la aclaración de puntos oscuros o rectificación de erratas.

En este orden de ideas, para delimitar estos problemas es un presupuesto necesario efectuar algunas precisiones conceptuales previas que permitan distinguir e individualizar a las diversas instituciones relacionadas con la revisión de oficio que contempla la LBPA. Para, luego, exponer los argumentos que establecen un concepto de revisión de oficio más amplio que el previsto por los aludidos derechos comparados, pero que se ajusta en mejor forma a la peculiar regulación chilena y que permite a la invalidación reconstituirse como un supuesto más de revisión de oficio.

\section{LAS VÍAS ADMINISTRATIVAS DE REVISIÓN Y LAS CAUSALES DE ELIMINACIÓN DE LOS ACTOS ADMINISTRATIVOS EN LBPA}

\section{La extinción natural de los actos administrativos}

La doctrina chilena ha identificado que los actos administrativos pueden extinguirse por dos causales primordiales. Una es la extinción natural o normal, que se caracteriza porque el acto perece cuando «se ha dado cumplimiento a su contenido u objeto» (Bermúdez, 2011: 129). De ahí que ha sido identificada como aquella extinción que se produce por el agotamiento del acto y que se determina porque la «eficacia (del acto) se va yendo paulatinamente en el tiempo, en la medida que se van produciendo los efectos previstos y queridos por el órgano emisor» (Olguín, 1961: 32). Flores (2016:192) completa lo anterior y formula que el acto administrativo también se extingue naturalmente con la operatividad de una cláusula accesoria que contenga un plazo o una condición. Por ejemplo, esto suele suceder con el nombramiento de un empleado público contratado a un plazo determinado, el que se extingue ipso iure una vez que transcurra el tiempo. En ocasiones es la ley la que fija este plazo o dispone un límite a dicho plazo ${ }^{7}$. Por tanto, la extinción natural

\footnotetext{
6 Anótese que la historia de la LBPA es estéril en este punto, pues no aporta más antecedentes que explicitar que el texto se mantuvo prácticamente idéntico durante toda la discusión legislativa. Así se puede cotejar en Biblioteca del Congreso Nacional, 2003: $96,121,254,306,316,335,347,398,426$ y 450.

7 V. g. la Ley núm. 18.834, de 1989, art. 10, dispone que «los empleos a contrata, durarán, como máximo, sólo hasta el 31 de diciembre de cada año y los empleados que los sirvan expirarán en sus funciones en esa fecha, por el solo ministerio de la ley (...)» (sic).
} 
de los actos administrativos se caracteriza por ocasionarse sin necesidad de que otro acto intervenga en el asunto. De modo que basta el mero trascurso del tiempo o la verificación de la condición para que el acto se extinga por el solo ministerio de la ley.

\section{La extinción provocada de los actos administrativos}

La extinción provocada o anticipada es precisamente lo opuesto a la extinción natural o normal, pues aquí hay un elemento diferenciador. Este es el advenimiento de una nueva declaración de voluntad de la Administración Pública o de un tribunal de justicia que dispone la destrucción de un acto administrativo anterior (Olguín, 1961: 34). Sentado esto, es menester señalar que alguna doctrina administrativa chilena, inexactamente a nuestro entender, suele indicar que las causales que motivan la extinción de los actos administrativos son la invalidación, la revocación por motivos de oportunidad, la caducidad y la nulidad judicial. Así, por ejemplo, lo ha expresado Caldera (2001: 123), quien inmediatamente agrega que «las tres primeras casuales indicadas: la invalidación, la revocación y la caducidad son resueltas por la Administración directamente; en cambio la nulidad, es decretada por la Jurisdicción (...)»8.

De ahí que lo mencionado requiere de ciertas precisiones. En efecto, si observa con detención se puede advertir que la doctrina citada asemeja las causales o razones que motivan la extinción del acto administrativo con las vías o los medios destinados a obtener tal extinción. A nuestro entender, esa asimilación no es del todo correcta, pues son realmente causales de extinción provocada o anticipada de los actos administrativos la ilegalidad, la pérdida del mérito, oportunidad o conveniencia, el incumplimiento de ciertas condiciones, o la comisión de conductas ilícitas, pues cada una de aquellas, en la medida que la ley lo disponga, servirán de justificación para disponer la extinción de un acto administrativo. En cambio, las vías son los procesos administrativos o procedimientos administrativos ${ }^{9}$ por los que, justificados en alguna de las mencionadas causales, se emite una nueva declaración de voluntad que disponga la destrucción de un acto administrativo anterior ${ }^{10}$. Seguidamente, se puede afirmar que no es lo mismo indicar que la invalidación, la anulación y la revocación son causales de extinción (erradamente a nuestro parecer), que apuntar (como se sugiere) que la extinción del acto se produce por su anulación, invalidación o revocación.

En este orden de ideas, podemos organizar a las vías existentes en el ordenamiento jurídico chileno para obtener la eliminación anticipada de los actos administrativos en razón de la sede y la respectiva causal de extinción. Así, en primer lugar, se sitúa la vía judicial que contempla únicamente a la anulación por razones de ilegalidad. En segundo lugar, está la vía administrativa. Esta admite ser clasificada según la causal que sea procedente. Invalidación o eliminación por razones de ilegalidad; revocación en sentido estricto, vale decir por motivos de oportunidad; revocación-sanción, por la comisión de una conducta ilícita administrativa tipificada y así sancionada por la ley; revocación por caducidad del acto, es decir cuando se ha incumplido ciertas condiciones exigidas por la ley o por el mismo acto; y las vías recursivas, que en el caso chileno permiten la eliminación del acto tanto por ilegalidad como inconveniencia.

\section{Las vías de revisión reguladas en la LBPA}

En el contexto descrito, y para una mejor comprensión del asunto, pasamos a un breve análisis de las instituciones que se encuentran reguladas por capítulo IV de la LBPA, denominado «revisión de los actos administrativos». Estas son la invalidación, la revocación por motivos de oportunidad, la revocación en vía recursiva administrativa y, ahora, agregamos la aclaración de puntos oscuros o corrección de meros errores.

\footnotetext{
${ }^{8}$ En el mismo sentido, MORAGA (2010: 256 y 257) y CELIS (2016: 56).

${ }_{9}$ Anótese, que en el derecho administrativo chileno se reserva el enunciado procedimientos administrativos para cualquier medio destinado a la elaboración, modificación o extinción de un acto administrativo, incoado y resuelto por la Administración Pública. En cambio, la expresión procesos administrativos se emplea para referirse a las vías judiciales de impugnación de un acto administrativo (FERRADA, 2011: 253).

10 En ese entendido, nos parece razonable que la jurisprudencia nacional manifieste que «(...) la resolución de un acto administrativo (...) propio del derecho público, cuya extinción sólo puede acontecer por tres vías, a saber: por la vía natural, que opera con el agotamiento o cumplimiento del acto; por la vía administrativa, mediante la invalidación o revocación; y por la vía judicial a través de la declaración efectuada al efecto por sentencia legalmente pronunciada». Corte Suprema de Justicia, Sentencia de 16 de julio de 2012 , rol núm. 4120-2012. co. $4 .^{\circ}$.
} 


\section{a) La invalidación}

Esta es la denominación que recibe en sentido estricto la vía provocada o anticipada de extinción de los actos administrativos por razones de ilegalidad congénita y que se caracteriza por operar de oficio o a petición de parte en sede administrativa (Letelier, 2002: 699). Su regulación legal está prevista en el conciso artículo 53 de la LBPA:

«Invalidación. La autoridad administrativa podrá, de oficio o a petición de parte, invalidar los actos contrarios a derecho, previa audiencia del interesado, siempre que lo haga dentro de los dos años contados desde la notificación o publicación del acto. La invalidación de un acto administrativo podrá ser total o parcial. La invalidación parcial no afectará las disposiciones que sean independientes de la parte invalidada.

El acto invalidatorio será siempre impugnable ante los Tribunales de Justicia, en procedimiento breve y sumario».

De ahí que la doctrina chilena suele aseverar que «la invalidación consiste en la extinción del acto administrativo en razón de haber sido dictado éste en contra del ordenamiento jurídico, producto de un acto posterior en sentido contrario de la propia Administración Pública que lo ha dictado» (Bermúdez, 2005). En consecuencia, la primera particularidad de la invalidación que aflora, es que esta se trata de una forma de anulación de los actos administrativos viciados ${ }^{11}$. En ese sentido, «existe una identidad sustancial entre la invalidación y la nulidad (jurisdiccional), toda vez que ambas se constituyen en el efecto jurídico de un actuar ilegal (...). Sin perjuicio de concurrir una diferencia adjetiva desde el punto de vista de la sede y el procedimiento para requerir su declaración o su constatación» (Lara y Guerrero, 2011: 38). Por tanto, se desprende que la invalidación, al igual que en la nulidad jurisdiccional, posee un semblante sustancial y uno adjetivo.

En el aspecto sustantivo, la invalidación se justifica por la existencia de un acto administrativo ilegal en su sentido amplio o contrario a derecho, conforme a la expresión que emplea el citado Art. 53 de la LBPA ${ }^{12}$. Por consiguiente, la regla general que se desprende del mencionado precepto es que una infracción a cualquier cuerpo normativo podría provocar la invalidación de un acto administrativo. Por ello, no necesariamente debe tratarse de una contravención a ley en su sentido estricto, sino que también es motivo suficiente para invalidar, por ejemplo, la constatación de una infracción a la Constitución o un reglamento administrativo (Cárcamo, 2013). Luego, la excepcionalidad para invalidar prevista por la LBPA está dada, más bien, por la naturaleza o calidad del vicio que genera la afectación del acto. En efecto, conforme se desprende del inciso $2 .^{\circ}$ Art. 13 de la LBPA ${ }^{13}$, tratándose de actos administrativos poseedores de algún vicio de fondo o contrario al derecho sustantivo, en principio, son siempre invalidantes ${ }^{14}$. En cambio, si se trata de un vicio de procedimiento o de forma, la LBPA arremete disponiendo que estos no son invalidantes y por el contrario son esencialmente subsanables, pero en la medida que no se afecten intereses de terceros ni se refieran a

11 Empero, cabe destacar que la doctrina chilena ha reservado el vocablo nulidad para referirse exclusivamente a la vía jurisdiccional de extinción de los actos administrativos, pero con un exclusivo fin didáctico de diferenciarla de la vía administrativa para anularlos (OÑATE, 2013: 35).

12 Es menester destacar que los supuestos de la invalidación son los mismos que la anulación judicial. Tales supuestos, en general, han sido acotados por el máximo tribunal. Así este ha expresado que «(...) de acuerdo con la jurisprudencia asentada por esta Corte -y que recoge una doctrina que ha gozado de general aceptación- la ilegalidad de un acto administrativo, que puede acarrear su anulación, puede referirse a la ausencia de investidura regular, incompetencia del órgano, defectos de forma, desviación de poder, ilegalidad en cuanto a los motivos y violación de la ley de fondo aplicable» (sic). Corte Suprema de Justicia, Sentencia de 7 de marzo de 2018, rol núm. 34.277-2017. Co. 9. ${ }^{\circ}$

13 Ley núm. 19.980, de 2003, Art. 13 inc. $2 .^{\circ}$. «El vicio de procedimiento o de forma sólo afecta la validez del acto administrativo cuando recae en algún requisito esencial del mismo, sea por su naturaleza o por mandato del ordenamiento jurídico y genera perjuicio al interesado.

La Administración podrá subsanar los vicios de que adolezcan los actos que emita, siempre que con ello no se afectaren intereses de terceros».

14 La LBPA no ha establecido restricción alguna para invalidar, así se puede observar de su texto; sin embargo, la jurisprudencia de la Contraloría General de la República ha establecido ciertas restricciones al ejercicio de dicha potestad en razón de principios como la buena fe, la confianza legítima, la seguridad jurídica y los derechos adquiridos. Ejemplificador en ese aspecto es su Dictamen núm. 96.610, de 2010. «(...) cabe recordar que la jurisprudencia de esta Contraloría General, contenida, entre otros, en los dictámenes núms. 82.062, de 2013 y 2.420, de 2014, ha manifestado que la potestad invalidatoria de la autoridad tiene como límite aquellas situaciones jurídicas consolidadas sobre la base de la confianza de los particulares en la actuación legítima de los órganos de la Administración, de manera tal que las consecuencias de una medida de esta naturaleza no pueden afectar a terceros que adquirieron derechos de buena fe al amparo del acto impugnado (...)» (sic). 
un requisito esencial del acto previsto por el legislador, como ocurre, por ejemplo, con la carencia de motivación de los antecedentes y fundamentos que sirvieron de base para la dictación del acto ${ }^{15}$. De lo cual se desprende que no todo vicio de forma afectará la validez del acto administrativo.

En cuanto a su aspecto adjetivo, «la invalidación supone tanto un procedimiento administrativo como un acto administrativo final invalidatorio» (Bermúdez, 2005). Esto porque, si bien implica el ejercicio de una potestad de la Administración Pública para eliminar aquellos actos propios contrarios a derecho, dicha potestad no se ejerce inmediatamente, sino que debe concretarse mediante un procedimiento administrativo previo y que culmine con una declaración administrativa de invalidez contenida en el respectivo acto administrativo. De ahí, que la invalidación también se conciba como una expresión de la autotutela declarativa, por la cual la Administración, sin necesidad de tener que requerir la intervención de los tribunales de justicia ni el requerimiento de un tercero, resuelve la extinción de un acto administrativo. En ese sentido, la invalidación ha sido conceptualizada como «el poder o facultad de la Administración Pública de volver sobre sus actos propios -ya sea de oficio o a petición de parte-, para revisar y retirar por sí misma actos administrativos viciados, irregulares o contrarios al ordenamiento jurídico, mediante un acto invalidatorio de signo contrario» (Millar, 2013: 383). Por consiguiente, la invalidación en el sentido estricto se refiere la eliminación en vía administrativa por razones exclusivamente de ilegalidad.

\section{b) La revocación por motivos de oportunidad}

La doctrina nacional ha precisado que el concepto de invalidación se opone al de revocación. Así bien lo expresa Letelier (2002: 699), quien manifiesta que «podrá existir revocación cuando a través de un acto (normalmente discrecional) se priva de efectos a otra actuación en razón del mérito». En ese entendido, cabe precisar que el derecho administrativo chileno ha procurado reservar el vocablo revocación para referirse específicamente al retiro por motivos de oportunidad, mérito o conveniencia. Esto con el objetivo de poder diferenciarla del retiro por razones de legalidad que ya hemos especificado como invalidación.

Empero, cabe destacar que la distinción entre el empleo de las expresiones invalidación y revocación no es algo caprichoso ni una sutileza seguida por la doctrina y la jurisprudencia chilena, sino que surgió en las Primeras Jornadas Chileno-Uruguayas de Derecho (1958), en las que se acordó, con el fin de unificar el lenguaje doctrinario, que la invalidación consistiría en «la acción de retirar la Administración sus actos administrativos antijurídicos (...)» (Soto, 1989: 476 y 477). Así, el vocablo revocación se reservaría exclusivamente para el retiro de actos administrativos válidos, pero que han perdido el mérito en razón de los intereses generales y por ello se han vuelto inconvenientes o inoportunos.

Posteriormente, dicha terminología fue incorporada en el Dictamen núm. 89.271, de 1966, de la Contraloría General de la República ${ }^{16}$. De esta manera, la distinción en comento tuvo rápidamente aplicación en la práctica y jerga administrativa chilena, pero sin un sustento normativo de carácter general que las contemplara (Marín, 2002). Lo cual perduró hasta la dictación de la LBPA que finalmente adoptó tal distinción conforme se aprecia en sus Arts. 53 y 61.

Ahora bien, aun cuando el Art. 61 de la LBPA no ha definido en qué consiste la revocación, sino que solamente ha dispuesto cuándo no es procedente ${ }^{17}$, se desprende tanto de la historia legislativa de la LBPA

15 «(...) se exige que los actos de los órganos de la Administración del Estado tengan una motivación y un fundamento racional, ya que, conforme al principio de juridicidad, es necesario acreditar que estos no obedecen al mero capricho de la autoridad, sino que a hechos efectivos que le otorgan legitimidad al acto, situación que en la especie se cumpliría al tenor de lo que le fue informado a la recurrente en la carta de aviso previo de despido». Contraloría General de la República, Dictamen núm. 61.517, de 2012.

16 Esta institución es un órgano administrativo dotado de autonomía constitucional, frente al poder ejecutivo y demás órganos públicos. Es por tanto independiente de todos los ministerios, autoridades y oficinas de la Administración y del Estado. Respecto a sus atribuciones, estas han sido clasificadas en función jurídica, función de auditoría y función contable. La función jurídica, que es la que nos interesa, consiste en realizar el control de legalidad de los actos administrativos, mediante un pronunciamiento contenido en actos denominados dictámenes, los cuales a su vez conforman lo que se conoce como jurisprudencia administrativa. Estos dictámenes en su esencia son actos de juicio, es decir aquellos actos en que un órgano administrativo expresa el punto de vista correspondiente a sus competencias respectivas, pero por disposición legal deben ser obedecidos necesariamente por las Administraciones Públicas. dictado.

17 Ley núm. 19.880, de 2003, Art. 61. «Procedencia. Los actos administrativos podrán ser revocados por el órgano que los hubiere

La revocación no procederá en los siguientes casos:

a) Cuando se trate de actos declarativos o creadores de derechos adquiridos legítimamente;

b) cuando la ley haya determinado expresamente otra forma de extinción de los actos; o

c) cuando, por su naturaleza, la regulación legal del acto impida que sean dejados sin efecto». 
(Biblioteca del Congreso Nacional, 2003: 89, 172, 221, 370 y 376), como también de una interpretación armónica y coherente de sus diversos preceptos, que si una institución (invalidación) es por motivos de ilegalidad o contrariedad a derecho, la otra (revocación) por tanto es por motivos de oportunidad ${ }^{18}$.

La revocación por motivos de oportunidad también se particulariza por consistir en una manifestación de la autotutela declarativa, pues la Administración Pública que dictó el acto, sin necesidad de requerimiento de parte alguna y sin la intervención de los tribunales de justicia, sino que solo sometiéndose al respectivo procedimiento administrativo destinado a elaborar una nueva declaración de voluntad, puede disponer el retiro de un acto válido y eficaz en razón del interés público (Madariaga, 1993: 101).

Con todo, corresponde hacer mención que el vocablo revocación no solamente ha sido empleado en el sentido estricto al que hemos aludido, sino que también como equivalente a la expresión de retiro, vale decir como un concepto genérico que sirve para individualizar a cualquier eliminación provocada en la vía administrativa, sin importar la razón invocada para ello ${ }^{19}$. De ahí que -aun cuando nos parece que dicha noción de revocación no es la más acertada, pues puede inducir a errores ${ }^{20}$ - se debe dejar anotado que en Chile existen otras modalidades de eliminación que también suelen ser denominadas como revocación, como es la revocación-sanción o la revocación por caducidad, pero que en atención a que su estudio se aleja del objeto de este trabajo, en esta ocasión, no le prestamos atención.

\section{c) Las vías recursivas administrativas}

La doctrina comparada ha manifestado que el recurso administrativo «es un medio de revisión de los actos inválidos por la Administración, iniciado a instancia de un sujeto legitimado para ello y sujeto a un plazo de interposición» (Gamero y Fernández, 2009: 495). En ese sentido, lo manifestado por la citada doctrina está en concordancia con la regulación de la LBPA ${ }^{21}$. Por ello, un elemento de la esencia del recurso administrativo es que este constituye un instrumento impugnatorio del que pueden hacer uso principalmente los particulares o una Administración Pública ajena a la que dictó el acto. En efecto, esto se desprende de una interpretación lógica de la LBPA que indica, por un lado, quién es el sujeto legitimado para recurrir (Art. $21^{22}$ ) y, por otro, concede a la Administración autora otros medios idóneos para eliminar un acto. Así acontece que si el órgano de la Administración Pública que dictó el acto estima que este es ilegal deberá invalidar (Art. 53 LBPA) o sí lo estima importuno deberá revocar (Art. 61 LBPA). Lo mismo, si se percata de erratas deberá rectificar (Art. 62. LBPA), pero no recurrir en contra de sí misma.

En cuanto al objetivo de los recursos, si bien en principio es la impugnación de un acto administrativo en sede Administrativa, por disposición del citado Art. 15 de la LBPA no todos los actos administrativos son impugnables por medio de esta vía, sino que solamente aquellos de carácter terminal o resolutorio, es decir «que contienen el pronunciamiento sobre la cuestión de fondo que suscitó el procedimiento de gestión» (Cordero, 2003: 164). Asimismo, la LBPA permite excepcionalmente la impugnación de los actos

18 Así se ha visto reflejado en una reiterada e uniforme jurisprudencia de la Contraloría General de la República, que por ejemplo ha expresado que «la revocación consiste en la necesidad de retirar un acto administrativo, que es válido, del ordenamiento jurídico, dejándose sin efecto por la propia autoridad que lo dictó, en consideración a que vulnera el interés público general -esto es, por razones de justicia y no de legalidad-, decisión que, por ende, se funda en razones de mérito, conveniencia u oportunidad, entendiéndose limitada por la consumación de los efectos de aquel o por la existencia de derechos adquiridos (...)». Dictamen núm. 96.610, de 2015. Este mismo, hace referencia a otros dictámenes anteriores como son los números 2.196, de 1993; 2.641, de 2005; 8.058, de 2009; 35.081 , de 2014; y 59.466, de 2015.

19 La doctrina comparada ha conceptualizado a la revocación genérica como «la retirada definitiva por la Administración de un acto suyo anterior mediante otro de signo contrario» (GARCÍA DE ENTERRÍA Y FERNÁNDEZ, 2002: 651).

20 Ejemplificador es lo que acontece con la potestad contemplada y denominada como revocación en el Decreto Ley núm. 1.094, de 1975, sobre extranjeros en Chile, que permite a la autoridad administrativa eliminar, por sí misma, los visados otorgados a extranjeros que han ingresado o que permanecen en Chile en razón de supuestos que poseen diversas naturalezas jurídicas. De ahí que es posible hallar supuestos fundados no solo en motivos de oportunidad (lo que sería revocación propiamente tal), sino que también de ilegalidad (invalidación) y sancionatorios (revocación-sanción) (DELGADO, 2018: 1-31).

21 Ley núm. 19.880, de 2003, Art. 15 inc. 1. . «(...) Todo acto administrativo es impugnable por el interesado mediante los recursos administrativos de reposición y jerárquico, regulados en esta ley, sin perjuicio del recurso extraordinario de revisión y de los demás recursos que establezcan las leyes especiales».

22 Ley núm. 19.880, de 2003, Art. 24. «Se consideran interesados en el procedimiento administrativo:

1. Quienes lo promuevan como titulares de derechos o intereses individuales o colectivos.

2. Los que, sin haber iniciado el procedimiento, tengan derechos que puedan resultar afectados por la decisión que en el mismo se adopte.

3. Aquéllos cuyos intereses, individuales o colectivos, puedan resultar afectados por la resolución y se apersonen en el procedimiento en tanto no haya recaído resolución definitiva». 
de mero trámite, pero en la medida que determinen la imposibilidad de continuar un procedimiento o produzcan indefensión ${ }^{23}$.

Respecto al motivo que induce la interposición del recurso, el derecho administrativo chileno no hace distinción y por tanto se ha entendido que el sujeto afectado puede solicitar en su recurso tanto una invalidación como una revocación o una rectificación (Cordero, 2003: 160). Finalmente, es preciso señalar que la LBPA contempla con carácter ordinario al recurso de reposición ${ }^{24}$ y al jerárquico ${ }^{25}$. Con carácter excepcional al recurso de revisión extraordinario que solamente permite invocar algunos concretos motivos tasados por la ley ${ }^{26}$.

\section{d) La aclaración de puntos oscuros, dudosos y rectificación de meros errores}

La LBPA no ha restringido la noción de revisión únicamente para referirse a instancias de eliminación. Esto porque también es posible incoar, de oficio o petición de parte, un procedimiento de revisión, pero destinado a efectuar aclaraciones, meras correcciones de equivocaciones o errores no esenciales contenidos en el acto, como los aritméticos o materiales. Así lo dispone su Art. 62 , inserto dentro del párrafo $4 .{ }^{\circ}$ destinado a la revisión de oficio, el que expresa que «(...) en cualquier momento, la autoridad administrativa que hubiere dictado una decisión que ponga término a un procedimiento podrá, de oficio o a petición del interesado, aclarar los puntos dudosos u obscuros y rectificar los errores de copia, de referencia, de cálculos numéricos y, en general, los puramente materiales o de hechos que aparecieren de manifiesto en el acto administrativo».

En ese entendido, se aprecia que la LBPA amplía la noción de revisión de oficio, a una institución que no constituyen una especie de eliminación, sino que una vez solucionado el error o aclarado el punto dudoso, la irregularidad se habrá subsanado y por ende no se afectará en nada la subsistencia del acto revisado, sino que por el contrario se consolidará su permanencia.

\section{LA REVISIÓN DE OFICIO EN SENTIDO AMPLIO. UNA PROPUESTA DE INTERPRETACIÓN ARMÓNICA PARA EL DERECHO CHILENO}

Llegado a este punto, es menester recordar lo anunciado al principio de esta obra, vale decir que pareciera que la decisión legislativa chilena ha ido por el lado contrario a lo que se ha determinado como revisión de oficio por el derecho hispano que le ha servido de modelo. Es decir, de una primera lectura, aquello que la LBPA ha designado como revisión de oficio es la revocación por motivos de oportunidad y la aclaración de puntos dudosos o rectificación de errores, pero no así a la invalidación. En efecto, si bien dichas instituciones se encuentran dentro del capítulo IV de la LBPA, denominado revisión de los actos administrativos, el problema surge porque el Art. 53, que contempla exclusivamente a la invalidación, está ubicado en el párrafo $1 .^{\circ}$, titulado principios generales, y no en el párrafo $4 .^{\circ}$, denominado como revisión de oficio. De ahí que,

${ }^{23}$ Ley núm. 19.880, de 2003, Art. 15 inc. $2^{\circ}$. «Sin embargo, los actos de mero trámite son impugnables sólo cuando determinen la imposibilidad de continuar un procedimiento o produzcan indefensión».

${ }^{24}$ Ley núm. 19.880, de 2003, Art. 59 inc. 1.․ «(...) El recurso de reposición se interpondrá dentro del plazo de cinco días ante el mismo órgano que dictó el acto que se impugna; en subsidio, podrá interponerse el recurso jerárquico».

25 Ley núm. 19.880, de 2003, Art. 59 inc. $2 .^{\circ}$. «Rechazada total o parcialmente una reposición, se elevará el expediente al superior que corresponda si junto con ésta se hubiere interpuesto subsidiariamente recurso jerárquico».

26 Ley núm. 19.880, de 2003, «Párrafo 3.․ Del recurso extraordinario de revisión.

Artículo 60. En contra de los actos administrativos firmes podrá interponerse el recurso de revisión ante el superior jerárquico, si lo hubiere o, en su defecto, ante la autoridad que lo hubiere dictado, cuando concurra alguna de las siguientes circunstancias.

a) Que la resolución se hubiere dictado sin el debido emplazamiento;

b) que, al dictarlo, se hubiere incurrido en manifiesto error de hecho y que éste haya sido determinante para la decisión adoptada, o que aparecieren documentos de valor esencial para la resolución del asunto, ignorados al dictarse el acto o que no haya sido posible acompañarlos al expediente administrativo en aquel momento;

c) que por sentencia ejecutoriada se haya declarado que el acto se dictó como consecuencia de prevaricación,

cohecho, violencia u otra maquinación fraudulenta, y

d) que en la resolución hayan influido de modo esencial documentos o testimonios declarados falsos por sentencia ejecutoriada posterior a aquella resolución, o que siendo anterior, no hubiese sido conocida oportunamente por el interesado.

El plazo para interponer el recurso será de un año que se computará desde el día siguiente a aquél en que se dictó la resolución en los casos de las letras a) y b). Respecto de las letras c) y d), dicho plazo se contará desde que la sentencia quede ejecutoriada, salvo que ella preceda a la resolución cuya revisión se solicita, caso en el cual el plazo se computará desde el día siguiente al de la notificación de ésta. 
aun cuando el Art. 53 concede a las Administraciones Públicas la facultad para invalidar de oficio sus actos contrarios a derecho, se advierte en el citado párrafo $4 .{ }^{\circ}$ ausencia de normas que hagan alguna referencia a la invalidación.

En ese entendido, se considera que es necesario hallar una interpretación que permita también redimir, en algo, la verdadera naturaleza jurídica de la revisión de oficio, es decir que permita considerar a la invalidación, al menos, como uno más de sus supuestos. Algunas voces en el derecho administrativo chileno se han pronunciado sobre la materia (Fortes: 2006). Estas sugieren considerar que la noción de revisión de oficio de los actos administrativos puede llegar a ser entendida como el genus, es decir el género común del que posteriormente se podrían diferenciar dos especies. Estas serían la revocación y la invalidación. Aunque esa propuesta no es fiel reflejo de la revisión de oficio originaria, vale decir tanto de la hispana o la alemana, que se refieren exclusivamente al retiro por causas de ilegalidad, se considera suficientemente aceptable para la realidad jurídica chilena, ya que recobraría en algo el verdadero significado de la noción de revisión de oficio. Esto, especialmente, porque la evidencia legislativa no deja mucho margen para discrepar que la revocación por motivos de oportunidad y la aclaración de puntos dudosos o rectificación de errores no sean unos supuestos de revisión de oficio y por tanto es casi imposible descartarlas. Por ende, la solución que vislumbramos se inclina por sostener que la revisión de oficio en Chile es un género común que engloba varias especies.

De esta manera, consideramos que es más viable hallar una justificación que permita incorporar a la invalidación como uno más de los supuestos de revisión de oficio, que enfocarnos en negar que la revocación y la aclaración de puntos dudosos o rectificación de errores, para el derecho administrativo chileno, sean unos supuestos de revisión de oficio. Para validar tal conjetura corresponde, por tanto, esclarecer ciertas interrogantes. Una tiene relación sobre si efectivamente la invalidación, a pesar de no estar consagrada en el aludido párrafo $4 .^{\circ}$, dedicado a la revisión de oficio, se puede considerar como uno de sus supuestos. La otra interrogante es hallar alguna explicación que justifique porqué la LBPA no consideró a la invalidación dentro del citado párrafo $4 .{ }^{\circ}$.

\section{La invalidación como un supuesto de revisión de oficio de los actos administrativos}

En efecto, aun cuando la institución de la invalidación de los actos administrativos ha sido incorporada dentro del párrafo $1 .^{\circ}$, que como hemos indicado ha sido denominado como «principios generales», se pueden hallar argumentos de texto y semánticos suficientes para considerarla como uno de los supuestos de revisión de oficio.

En primer lugar, se debe anotar que la condición de revisión de oficio de la invalidación viene definida por el mismo tenor literal del Art. 53. Así, se puede observar que dicho precepto ha facultado a las Administraciones Públicas para que puedan invalidar sus actos contrarios a derecho tanto a petición de parte como de oficio. En ese sentido, la expresión de oficio es determinante para nuestro análisis, pues está en plena concordancia con el significado que le otorga la Real Academia Española ${ }^{27}$, vale decir el enunciado de oficio indica que se habilita a las Administraciones Públicas para reaccionar e impulsar la revisión de algún acto que se estime viciado, sin la necesidad de tener que ser requeridas por algún tercero. Esta idea se reafirma por un criterio ya asentado en la Contraloría General de la República, que considera que si la Administración se ha percatado de algún vicio invalidante, le surge una obligación ineludible de restaurar el imperio del derecho quebrantado, mediante la respectiva invalidación del acto viciado. Por tanto, la Administración deberá iniciar el procedimiento de revisión de oficio sin más trámite que solo atenerse a las respectivas normas procedimentales ${ }^{28}$. Así, aun cuando el tenor literal del Art. 53 de la LBPA señala que «la autoridad administrativa podrá invalidar (...)» y con ello pareciera que se le otorga una potestad de ejercicio meramente facultativo, la existencia de un acto viciado de tal gravedad que genere una verdadera contrariedad al derecho, en realidad, implica un imperativo jurídico para el órgano administrativo emisor del acto o su superior jerárquico, en su caso, de disponer su invalidación (Cárcamo, 2013). Entender lo contrario, significaría que el ejercicio de la potestad invalidatoria quedaría entregado a la discreción o mera voluntad de la Administración y, con ello,

27 De oficio: «dicho de una diligencia, que se practica judicialmente sin instancia de parte». Real Academia Española (2018).

28 «(...) si la Administración hubiese detectado vicios que afectaran la legalidad de la adjudicación y del posterior contrato, lo que procedía era iniciar un proceso de invalidación dentro de los dos años siguientes a la notificación de los actos». Contraloría General de la República, Dictamen núm. 76.032, de 2015. 
se vulneraría abiertamente el principio de juridicidad en el caso que esta última decida no invalidar, debiendo haberlo hecho ${ }^{29}$.

Por otro lado, la regulación que la LBPA ha hecho respecto a la aclaración de puntos oscuros o rectificación de meros errores también es determinante para afirmar que la invalidación es un supuesto más de revisión de oficio. Esto, porque a pesar de que la aclaración de puntos oscuros o rectificación de erratas esté consagrada en el aludido párrafo $4 .^{\circ}$ destinado a la revisión de oficio, el Art. 62 indica que, además de proceder de oficio, esta podrá ser solicitada a requerimiento de parte ${ }^{30}$. Así se vislumbra cierta flexibilidad de la LBPA respecto a lo que sus títulos o epígrafes realmente dicen contener. De esta manera, si el mencionado Art. 62, inserto en el párrafo destinado a la revisión de oficio, permite que la aclaración de puntos oscuros o rectificación de erratas pueda ser a petición de parte, por tanto, resulta lógico que la invalidación, aunque esté fuera del párrafo $4 .^{\circ}$ destinado a la revisión de oficio, también pueda ser considerada como uno de sus supuestos.

Por consiguiente, al permitir la LBPA que el procedimiento de invalidación en contra de un acto ilegal sea por iniciativa de la propia de la Administración -esto es de oficio- se desprende una consecuencia ineludible. Esta es la restitución de la invalidación como un supuesto más de revisión de oficio de los actos administrativos.

\section{Una justificación de por qué la LBPA no consideró a la invalidación dentro del citado párrafo $4 .^{\circ}$ dedicado a la revisión de oficio}

A nuestro parecer, la respuesta de por qué la LBPA ha dejado fuera a la invalidación del párrafo destinado a la revisión de oficio, se debe a dos razones.

La primera, se inclina por interpretar que la intención del legislador chileno fue disponer que la revocación por motivos de oportunidad no pueda ser requerida a petición de parte, sino que únicamente pueda operar de oficio. A diferencia de la invalidación, la cual puede acontecer tanto de oficio como a petición de parte. En efecto, «cuando el legislador regula la invalidación se refiere al retiro de actos administrativos por causa de ilegalidad; mientras que, cuando regula la revocación, da un sentido estricto al término, sólo comprensivo del retiro de actos administrativos por causa de mérito, oportunidad o conveniencia. Quedando claro, que el criterio de distinción entre ambas expresiones es objetivo, es decir, basado en el motivo o fundamento que autoriza el ejercicio de cada uno de los poderes respectivos» (Millar, 2008: 25 y 26). De esta manera, se vislumbra que el objeto de la revocación y, por ende, del principal supuesto de revisión de oficio escogido por la LBPA, es la extinción de un acto administrativo válido en conformidad a un criterio subjetivo de la propia Administración, derivado de su ineludible deber de tutelar los intereses generales y satisfacer las necesidades públicas siempre cambiantes. De ahí que el sentido que toma el concepto de revisión de oficio al vincularlo al de revocación es de un examen o análisis, pero no retrospectivo, sino que coetáneo o presente. Por ende, lo que se revisa, no son los elementos que conformaron o elaboraron el acto, sino que la conveniencia de conservar el acto y la correlativa producción de efectos hacia el futuro en relación a circunstancias coetáneas al tiempo que se decide su eliminación.

En ese sentido, si la razón o causa de la revocación propiamente tal es consecuencia de la calificación del mérito, oportunidad o conveniencia que una Administración realiza de un acto administrativo, supone por tanto que dicha apreciación consiste en una prerrogativa discrecional inherente a la función administrativa y que cada Administración podrá ponderar conforme a lo que a ella le parezca más correcto en razón del bien común o específico del organismo. De ahí que, como bien lo afirma la doctrina nacional, ocurre que «a diferencia de la potestad invalidatoria, se reconoce que la revocación administrativa constituye una manifestación específica de la apreciación del interés general en un momento determinado, que el legislador le entrega en forma exclusiva y excluyente a los órganos administrativos, para que a través del ejercicio de

29 «(...) en armonía con lo dispuesto en los artículos $6 .^{\circ}$ y $7 .^{\circ}$ de la Constitución Política de la República y $2 .^{\circ}$ de la ley núm. 18.575 , Orgánica Constitucional de Bases Generales de la Administración del Estado, que consagran el principio de juridicidad, la autoridad se encuentra en el imperativo de invalidar sus actos ilegales, con el propósito de restablecer el orden jurídico quebrantado por una decisión contraria a derecho, en tanto que con esa medida no se lesionen los derechos adquiridos por terceros». Contraloría General de la República, Dictamen núm. 52.771, de 2011.

30 Ley núm. 19.880, de 2003, Art. 62. «Aclaración del acto. En cualquier momento, la autoridad administrativa que hubiere dictado una decisión que ponga término a un procedimiento podrá, de oficio o a petición del interesado, aclarar los puntos dudosos u obscuros y rectificar los errores de copia, de referencia, de cálculos numéricos y, en general, los puramente materiales o de hechos que aparecieren de manifiesto en el acto administrativo». 
la potestad revocatoria aprecien y califiquen la vigencia de un determinado acto administrativo frente a los cambios de circunstancias que lo convierten en incompatible con el interés general» (Flores, 2016: 202).

En este orden de ideas, evidentemente es posible advertir que ciertamente un particular podrá efectuar alguna petición de revocación de un determinado acto administrativo. Sin embargo, aquello debe concebirse exclusivamente como comprensible de un mero ejercicio del derecho de petición que todos pueden hacer a la autoridad ${ }^{31}$, y el que necesariamente deberá tener una respuesta por parte del órgano requerido ${ }^{32}$, pero no por ello implicará un compromiso y un deber de revocar. Esto porque «la posibilidad de exigir una revocación obligatoria, significaría una intromisión en la función de administrar, puesto que es el sujeto administrativo quien puede y debe apreciar el interés público, obrando en consecuencia» (Olguín, 1961: 186).

De esta manera, resulta que para la LBPA solamente es la autoridad administrativa quien, en exclusividad, posee la discrecionalidad de impulsar de oficio el procedimiento administrativo de revocación de un acto administrativo y, luego, conforme a la valoración que esta tenga sobre la conveniencia o mérito que reporta la conservación del acto, para el resguardo de los intereses generales o específicos del órgano, decidirá si lo extingue. Situación en la que no se encuentra la invalidación, ni la aclaración de puntos oscuros o rectificación de erratas, pues constatada la existencia de alguna irregularidad ineludiblemente deberá invalidar, aclarar o rectificar, según corresponda.

Ahora bien, ciertamente lo idóneo habría sido que el legislador incluyera a la invalidación dentro del párrafo $4 .^{\circ}$ denominado de la revisión de oficio y, al igual que la rectificación de erratas, permitiera a través de la respectiva clausula excepcional la posibilidad de que la invalidación también se pudiera pedir a requerimiento de parte, es decir que se hubiera mantenido la misma redacción, pero dentro del aludido párrafo.

Sin embargo, la realidad normativa no es así. De ahí que aún es menester responder el porqué de la inclusión de la invalidación en el párrafo $1 .{ }^{\circ}$ de los «principios generales».

Así, según nuestro juicio, la segunda razón consiste en que la interpretación idónea se encamina por entender que la invalidez de un acto administrativo no solo puede ser alegada mediante el procedimiento administrativo destinado específicamente para ese efecto (nos referimos al del Art. 53 de la LBPA), sino que también puede ser el fundamento de cualquier recurso administrativo. Así, aparece como una consecuencia lógica que la inclusión de la invalidación en un párrafo denominado «principios generales» se debe a que son reglas comunes tanto para los recursos administrativos como para la revisión de oficio. Esto es, que se puede producir invalidación por motivos de legalidad tanto al hilo de un recurso administrativo, pero que también se puede producir de oficio.

Por tanto, conforme a lo expuesto, se visualiza que una explicación coherente que permita comprender el sistema de revisión de oficio elaborado por la LBPA, es que esta no puede ser concebida como una versión idéntica a lo que acontece en sus homologas hispana o alemana. De ahí que, debe ser entendida más bien como un género, del cual se extraen tres especies menores. En primer lugar, la invalidación o revisión por motivos de ilegalidad. En segundo lugar, la revocación por motivos de oportunidad. Y en tercer lugar, la aclaración de puntos dudosos o rectificación de meros errores.

\section{CONCLUSIONES}

La revisión de oficio de los actos administrativos chilena ha sido configurada por el legislador de una manera heterogénea en cuanto a su estructuración. Por tanto no se condice exactamente con su homóloga hispana que le ha servido de principal modelo. En ese sentido, se ha establecido que -en el derecho administrativo chileno- la revisión de oficio se debe concebir como un género que contiene tres especies menores, vale decir a la invalidación, a la revocación por motivos de oportunidad y a la aclaración de puntos oscuros o rectificación de erratas.

31 En la doctrina chilena, se ha sostenido que todo ciudadano tiene el derecho a hacer peticiones a la Administración sobre cualquier materia de interés general. Este derecho está consagrado en la Constitución y entre dichas peticiones, la posibilidad de solicitar que se revoque un determinado acto por ser inoportuno (OLGUÍN, 1961: 111).

32 «No obstante, considerando que el derecho de petición consagrado en el artículo 19 núm. 14 de la Carta Fundamental, conlleva la obligación de los entes públicos de responder las solicitudes de los administrados, lo que en derecho proceda, deben por ello adoptar en un plazo prudencial, una determinación frente a lo pedido, sea acogiendo o denegando lo solicitado, o bien, cuando carezcan de competencia deben limitarse a declarar ese hecho, dándose debido conocimiento de la respuesta al solicitante, la que por razones de certeza y buena técnica administrativa debe constar por escrito». Contraloría General de la República, Dictamen núm. 1.422, de 2002. 
Esto lo hemos fundamentado en que calificado que la evidencia legislativa no deja mucho margen para negar que la revocación por motivos de oportunidad y a la aclaración de puntos oscuros o rectificación de erratas sean verdaderas especies de revisión de oficio, se ha estimado que es más razonable justificar que la invalidación, aun cuando no está en el párrafo destinado a la revisión de oficio, si es otro de sus supuestos.

Para lo anterior, se ha recurrido a una interpretación que va más allá del mero tenor del Art. 53 de la LBPA, pues este solamente expresa una consecuencia ineludible. Esto es que la condición de oficio de la invalidación emana de su propia naturaleza, pues si la Administración que dictó el acto se percata de la existencia de la anomalía, le surge el deber de reestablecer el imperio del derecho, es decir debe invalidar el acto viciado sin la necesidad de tener que esperar el requerimiento de parte alguna. Así, con ese razonamiento se restituye a la invalidación como un supuesto más de revisión de oficio.

Asimismo, se ha establecido que para la LBPA la autoridad administrativa es la única que posee la discrecionalidad de impulsar de oficio el procedimiento administrativo de revocación de un acto administrativo, conforme a la valoración que esta tenga sobre la conveniencia o mérito que reporta la conservación del acto, para el resguardo de los intereses generales o específicos del órgano, y decidir si lo retira o extingue. De ahí que se comprende su designación como revisión de oficio.

Finalmente, se ha establecido que si se interpreta que la decisión del legislador chileno fue considerar que las reglas fijadas a la invalidación son normas generales (o sea aplicables tanto para la modalidad de oficio como para la vía recursiva), se justifica que la invalidación haya quedado fuera del citado párrafo $4 .^{\circ}$ denominado «revisión de oficio».

\section{REFERENCIAS BIBLIOGRÁFICAS}

ABARCA, J. (2015): “La invalidación administrativa en materia ambiental”, en Revista lus Publicum, núm. 34, págs. 99110. [16-09-2018] Disponible en web: http://www.ust.cl/wp-content/uploads/sites/6/2017/12/IUS-PUBLICUMN\%C2\%B0-34-2015.pdf.

ARÓSTICA, I. (1984): "La extinción de los actos administrativos y la jurisprudencia reciente de los tribunales de justicia”, en Revista chilena de Derecho, vol. 11, núm. 2/3, págs. 433-448.

BERMÚDEZ, J. (2005): "El Principio de Confianza Legítima en la actuación de la Administración como límite a la Potestad Invalidatoria", en Revista de Derecho de la Universidad Austral de Chile [online], vol. 18, núm. 2. DOI: $10.4067 / S 0718-09502005000200004$.

BERMÚDEZ, J. (2011): Derecho administrativo general. Santiago: Legal Publishing.

BIBLIOTECA DEL CONGRESO NACIONAL (2003): Historia de la Ley, núm. 19.880, que establece base de los procedimientos administrativos que rigen de los órganos de la administración del Estado. [16-01-2018] Disponible en web: http://www.bcn.cl/historiadelaley/nc/historia-de-la-ley/5844/.

BOCANEGRA, R. (2012): Lecciones sobre el acto administrativo. Pamplona: Aranzadi.

CALDERA, H. (2001): Tratado de derecho administrativo, Tomo II. Santiago: Parlamento Ltda.

CÁRCAMO, A. (2013): "La potestad invalidatoria de la Administración del Estado a diez años de la entrada en vigencia de la ley núm. 19.880. Una revisión de sus principales aspectos", en Diario Constitucional.cl. [20-05-2018] Disponible en web: http://diarioconstitucional.cl/articulos/la-potestad-invalidatoria-de-la-administracion-del-estadoa-diez-anos-de-la-entrada-en-vigencia-de-la-ley-n-19880-una-revision-de-sus-principales-aspectos/.

CELIS, G. (2016): Acto y procedimiento administrativo. Santiago: El Jurista.

CORDERO, L. (2003): El procedimiento administrativo. Santiago: LexisNexis.

DELGADO, A. (2018): "El sentido de la expresión revocación de visados, contenida en el Decreto Ley de Extranjería", en Revista Derecho y Crítica Social, vol. 4, núm. 1, págs. 1-31. [10-10-2018] Disponible en web: https:// derechoycriticasocial.files.wordpress.com/2018/09/1-delgado1.pdf.

ESTEVE, J. (2012): Lecciones de derecho administrativo. Madrid: Marcial Pons.

FERRADA, J. C. (2011): "Los procesos administrativos en el derecho chileno", en Revista de Derecho de la Pontificia Universidad Católica de Valparaíso, vol. 36, núm. 1, págs. 251-277. DOI: 10.4067/S0718-68512011000100007.

FLORES, J. C. (2016): "La caducidad de los actos administrativos", en Revista de Derecho (Valdivia), vol. 30, núm. 2, págs. 225-249. DOI: 10.4067/S0718-09502017000200010.

FORTES, A. (2006): "Estudio sobre la revocación de los actos administrativos", en Revista de derecho de la Universidad Austral de Chile, vol. 19, núm. 1, págs. 149-177. DOI: 10.4067/S0718-09502006000100007.

GAMERO, E. y FERNÁNDEZ, S. (2009): Manual básico de Derecho Administrativo. Madrid: Tecnos.

GARCÍA DE ENTERRÍA, E. y FERNÁNDEZ, T. R. (2002): Curso de Derecho Administrativo I. Madrid: Civitas.

LARA, J. L. y GUERRERO, G. (2011): "Aspectos críticos de la invalidación administrativa en la Ley 19.880: Análisis en la jurisprudencia de la Contraloría General de la República a 8 años de su vigencia”, en Revista de Derecho Escuela de Postgrado, núm. 1, págs. 17-44. DOI: 10.5354/0719-1731.2011.21153. 
LETELIER, R. (2002): "Un mal día no es eterno: Seis alcances en materia de invalidación y nulidad de los actos administrativos", en Revista de Derecho de la Universidad de Concepción, vol. 212, núm. 2, págs. 693-730. [2010-2018] Disponible en web: $h$ ttp://www.revistadederecho.com/pdf.php?id=2804.

MADARIAGA, M. (1993): Seguridad jurídica y administración pública en el siglo XXI. Santiago: Editorial Jurídica de Chile.

MARÍN, U. (2002): "Vigencia actual de la invalidación de los actos administrativo", en Revista de derecho del Consejo de Defensa del Estado, núm. 2. [10-02-2018] Disponible en web: https://www.cde.cl/wps/wcm/connect/185d04b496ad-46ab-a207-adec82b25fe9/3.pdf?MOD=AJPERES.

MAURER, H. (2012): Derecho administrativo alemán. México: Universidad Nacional Autónoma de México.

MILLAR, J. (2008): La potestad invalidatoria en el derecho chileno (tesis doctoral). Santiago: Universidad de Chile, Facultad de Derecho. [10-10-2018] Disponible en web: http://repositorio.conicyt.cl/handle/10533/179627.

MILLAR, J. (2013): "El procedimiento administrativo de invalidación y los procesos de nulidad ante los tribunales de justicia", en VV.AA., FERRADA, J. C. (coord.): La nulidad de los actos administrativos en el Derecho Chileno, págs. 379-374. Santiago: Legal Publishing.

MORAGA, C. (2010): Tratado de derecho administrativo. La actividad formal de la Administración del Estado, Tomo VII. Santiago: Abeledo Perrot-Legal Publishing.

OLGUÍN, H. (1961): Extinción de los actos administrativos: revocación, invalidación y decaimiento. Santiago: Editorial Jurídica de Chile.

OÑATE, E. (2013): "La nulidad de Derecho público, una sanción de excepción", en VV.AA., FERRADA, J. C. (coord.): La nulidad de los actos administrativos en el Derecho Chileno, págs. 29-47. Santiago: Legal Publishing.

REBOLLO, M. y CARBONELL, E. (2016): "La revisión de oficio", en VV.AA., REBOLLO, M. y CARBONELL, E. (coords.): Derecho administrativo, Tomo II: Régimen jurídico básico y control de la Administración, págs. 197-216. Madrid: Tecnos.

REYES, J. (2002): Invalidación de actos administrativos. Santiago: LexisNexis.

SILVA, E. (1995): Derecho administrativo chileno y comparado. Actos, contratos y bienes. Santiago: Editorial Jurídica de Chile.

SOTO, E. (1989): "Invalidación de los actos administrativos", en Revista chilena de derecho, núm. 16, págs. 475-485. [15-06-2018] Disponible en web: https://dialnet.unirioja.es/servlet/articulo?codigo=2649667. 